\title{
Association Between SARS-CoV-2 RNAemia and Post-Acute Sequelae of COVID-19.
}

Nikhil Ram-Mohan $\mathrm{PhD}^{1}$, David Kim MD $\mathrm{PhD}^{1}$, Angela J Rogers MD MPH ${ }^{2}$, Catherine A Blish

$\mathrm{MD} \mathrm{PhD}^{3}$, Kari C Nadeau MD PhD ${ }^{2}$, Andra L Blomkalns $\mathrm{MD}^{1}$, Samuel Yang $\mathrm{MD}^{1^{*}}$

${ }^{1}$ Department of Emergency Medicine, Stanford University School of Medicine, Palo Alto CA 94305 USA

${ }^{2}$ Department of Medicine - Pulmonary, Allergy \& Critical Care Medicine, Stanford University School of Medicine, Palo Alto CA 94305 USA

${ }^{3}$ Department of Medicine/Infectious Diseases, Stanford University School of Medicine, Palo Alto CA 94305 USA

* Correspondence to:

\section{Funding}

This work was supported by NIH/NIAID (Grants R01AI153133, R01AI137272, and 


\section{Abstract}

39 Determinants of Post-Acute Sequelae of COVID-19 are not known. Here we show that $75 \%$ of

40 patients with viral RNA in blood (RNAemia) at presentation were symptomatic in the post-acute

41 phase. RNAemia at presentation successfully predicted PASC, independent of patient

42 demographics, initial disease severity, and length of symptoms.

43

\section{Keywords}

45

46

SARS-CoV-2, RNAemia, PASC, long COVID

47

48

49

50

51

52

53

54

55

56

57

58

59 


\section{Background}

62 The determinants of COVID-19 severity and extrapulmonary complications have now been well

63 studied, and RNAemia (viral RNA in blood) has emerged as an important factor $(1,2)$. Much less

64 is known about the determinants of Post-Acute Sequelae of COVID-19 (PASC), the persistence

65 or development of new symptoms after the acute phase of infection, recently reported to affect as

66 many as $87.4 \%$ of COVID-19 patients $(3,4)$ primarily with moderate or worse severity $(5,6)$.

67 Recent evidence suggested persistent clotting protein pathology with elevated levels of 68 antiplasmin (7) and non-classical monocytes (8) in patients with PASC. Discovery of SARS-

69 CoV-2 S1 protein in these non-classical monocytes and fragmented SARS-CoV-2 RNA in

70 peripheral blood mononuclear cells in a PASC patient 15 months post infection further exhibited

71 the persistence of viral particles (8). Given the importance of RNAemia in disease severity and

72 its persistence in the blood, we describe the relationship between RNAemia at presentation and

73 post-acute symptoms at least three weeks after symptom onset.

\section{Methods}

77 We studied the clinical trajectories of 155 patients enrolled in the IRB-approved (eP-55650)

78 Stanford Hospital Emergency Department (ED) COVID-19 Biobank between April and

79 November 2020 with completed follow-ups. We assessed symptoms and severity (based on a

80 modified WHO scale) (1) on the date of enrollment (median $=4$, range $=0-44$ days after

81 symptom onset), and at least three weeks after symptom onset (median $=35$, range $=21-79$

82 days). 
84 We measured SARS-CoV-2 RNAemia at the time of enrollment, using the definitions of our

85 earlier study (1). We compared the proportions of initially RNAemic and non-RNAemic patients

86 with persistent or new symptoms in the post-acute phase using a 2-sample chi-squared test with

87 continuity correction. We estimated the association between RNAemia at enrollment and PASC

88 at follow-up in a logistic model controlling for disease severity at enrollment, patient

89 demographics (age and gender), presence of any symptom at enrollment (anxiety, dizziness,

90 fatigue, hair loss, palpitations, rash, insomnia, chest pain, chills, cough, decrease in sense of

91 taste, fever, nausea/vomiting/diarrhea, headache, loss of smell, myalgia, new confusion,

92 shortness of breath), and durations of symptoms. We also compared the median number of PASC

93 symptoms for RNAemic and non-RNAemic patients using the Wilcoxon rank-sum test with

94 continuity correction. We performed all analyses in $\mathrm{R}$ (version 4.0.3).

95

96 Results

97

$9849.0 \%(76 / 155)$ of patients were women, and the median age was 45 years (IQR $34-60)$. At

99 enrollment, $27.1 \%(42 / 155)$ of patients had mild disease severity, $67.7 \%(105 / 155)$ moderate,

100 and 5.2\% (8/155) severe. Patients had a median of six symptoms (IQR = 4-8): 72.3\% (112/155)

101 had a cough, $65.3 \%(101 / 155)$ had shortness of breath, and 64.5\% (99/155) had fever. In the

102 post-acute phase, $52.3 \%(81 / 155)$ had one or more new $(24.5 \%$ [38/155]) or persistent $(37.4 \%$

103 [58/155]) symptoms, of which the most common were cough, dizziness, and loss of smell (Table

104 1). $1.3 \%(2 / 155)$ of patients developed anxiety that was not present at enrollment. 
$10675.0 \%(27 / 36)$ of initially RNAemic patients were symptomatic in the post-acute phase, 107 compared to $43.7 \%(52 / 119)$ of non-RNAemic patients (difference $=31.3 \%$ [95\% CI, $12.8 \%$ -

108 49.8\%], $\mathrm{p}=0.002$ ). RNAemic patients had a median of one symptom in the post-acute phase

109 compared to zero in non-RNAemic patients ( $\mathrm{p}=0.014$, Wilcoxon rank-sum test). RNAemia at 110 presentation predicted PASC, conditional on patient demographics and initial disease severity

111 (OR 1.31 [95\% CI, $1.08-1.59], \mathrm{p}=0.007$ (Supplement)). The association was strongest for 112 patients with moderate disease severity at presentation (Figure), with $78.6 \%(22 / 28)$ of initially

113 RNAemic patients symptomatic in the post-acute phase, compared to $45.5 \%$ (35/77) of non-

114 RNAemic patients (difference $=33.1 \%$ [95\% CI, $11.8 \%-54.4 \%], \mathrm{p}=0.005$ ). This difference was 115 due almost entirely to persistent or new respiratory symptoms (difference in proportions $=28.2 \%$ 116 [95\% CI, 8.4\% - 47.9\%], $\mathrm{p}=0.002)$.

118 Discussion

120 To our knowledge, this study describes the first reported association between SARS-CoV-2

121 RNAemia and PASC. RNAemia at presentation was associated with new or persistent symptoms

122 at least 21 days after symptom onset independent of initial patient severity and the association

123 was strongest among patients with moderately severe clinical presentations requiring hospital 124 admission. This finding adds to the growing literature on SARS-CoV-2 RNAemia's role in 125 disease severity and extrapulmonary complications in the acute phase of illness, as well as the 126 association between hospitalization and PASC $(1,2,5,6)$. The incidence of PASC was lower in 127 this single-center study than in reports from Italy and the UK $(3,4)$, but similar to that reported in 128 a recent study from the US (9). The potential contributions of patient characteristics, study 
methodologies, and viral variants to these discrepancies merit further study. Though the

130 mechanisms underlying RNAemia's contributions to multi-system pathology in both the acute

131 and post-acute phases, when persistent, remain to be elucidated, mounting evidence for its

132 predictive value suggests that testing for SARS-CoV-2 RNAemia at presentation may help guide

133 the triage, management, and prognosis of COVID-19.

134

135

136

137

138

139

140

141

142

143

144

145

146

147

148

149

150

151

152

153

154

155

156

157

158

159

160

161

162

Acknowledgements: The authors would like to thank the additional author members of the Stanford COVID-19 Biobank Study Group include: Elizabeth J Zudock, Marjan M Hashemi, Kristel C Tjandra, Jennifer A Newberry, James V Quinn, Ruth O'Hara, Euan Ashley, Rosen Mann, Anita Visweswaran, Thanmayi Ranganath, Jonasel Roque, Monali Manohar, Hena Naz Din, Komal Kumar, Kathryn Jee, Brigit Noon, Jill Anderson, Bethany Fay, Donald Schreiber, Nancy Zhao, Rosemary Vergara, Julia McKechnie, Aaron Wilk, Lauren de la Parte, Kathleen Whittle Dantzler, Maureen Ty, Nimish Kathale, Arjun Rustagi, Giovanny Martinez-Colon, Geoff Ivison, Ruoxi Pi, Maddie Lee, Rachel Brewer, Taylor Hollis, Andrea Baird, Michele Ugur, Drina Bogusch, Georgie Nahass, Kazim Haider, Kim Quyen Thi Tran, Laura Simpson, Michal Tal, Iris Chang, Evan Do, Andrea Fernandes, Allie Lee, Neera Ahuja, Theo Snow, James Krempski. We would also like to thank Hien Nguyen, Lingxia Jiang, and Paul Hung from COMBiNATi Inc. for all the material and technical support.

Disclosures: Yang is a Scientific Advisory Board member of COMBiNATi Inc.

\section{References}

1. Ram-Mohan N, Kim D, Zudock EJ, Hashemi MM, Tjandra KC, Rogers AJ, et al. SARSCoV-2 RNAemia predicts clinical deterioration and extrapulmonary complications from COVID-19. Clinical Infectious Diseases. 2021 May 5;ciab394.

2. The Massachusetts Consortium for Pathogen Readiness, Fajnzylber J, Regan J, Coxen K, Corry H, Wong C, et al. SARS-CoV-2 viral load is associated with increased disease severity and mortality. Nat Commun. 2020 Dec;11(1):5493.

3. Carfî A, Bernabei R, Landi F, for the Gemelli Against COVID-19 Post-Acute Care Study Group. Persistent Symptoms in Patients After Acute COVID-19. JAMA. 2020 Aug 11;324(6):603.

4. Arnold DT, Hamilton FW, Milne A, Morley AJ, Viner J, Attwood M, et al. Patient outcomes after hospitalisation with COVID-19 and implications for follow-up: results from a prospective UK cohort. Thorax. 2021 Apr;76(4):399-401. 
5. Lund LC, Hallas J, Nielsen H, Koch A, Mogensen SH, Brun NC, et al. Post-acute effects of SARS-CoV-2 infection in individuals not requiring hospital admission: a Danish populationbased cohort study. The Lancet Infectious Diseases. 2021 May;S1473309921002115.

6. Hirschtick JL, Titus AR, Slocum E, Power LE, Hirschtick RE, Elliott MR, et al. Populationbased estimates of post-acute sequelae of SARS-CoV-2 infection (PASC) prevalence and characteristics. Clinical Infectious Diseases. 2021 May 19;ciab408.

7. Pretorius E, Vlok M, Venter C, Bezuidenhout JA, Laubscher GJ, Steenkamp J, et al. Persistent clotting protein pathology in Long COVID/ Post-Acute Sequelae of COVID-19 (PASC) is accompanied by increased levels of antiplasmin [Internet]. Infectious Diseases (except HIV/AIDS); 2021 May [cited 2021 Aug 30]. Available from: http://medrxiv.org/lookup/doi/10.1101/2021.05.21.21257578

8. Patterson BK, Francisco EB, Yogendra R, Long E, Pise A, Rodrigues H, et al. Persistence of SARS CoV-2 S1 Protein in CD16+ Monocytes in Post-Acute Sequelae of COVID-19 (PASC) Up to 15 Months Post-Infection [Internet]. Immunology; 2021 Jun [cited 2021 Aug 28]. Available from: http://biorxiv.org/lookup/doi/10.1101/2021.06.25.449905

9. Chopra V, Flanders SA, O'Malley M, Malani AN, Prescott HC. Sixty-Day Outcomes Among Patients Hospitalized With COVID-19. Ann Intern Med. 2020 Nov 11;M20-5661. 
Tables and Figures

187 Table: Progression of COVID-19 symptoms

\begin{tabular}{llll}
\hline Symptom & On enrollment & $\begin{array}{l}\text { Persistent at } \\
\text { follow-up }\end{array}$ & $\begin{array}{l}\text { New at follow- } \\
\text { cup }\end{array}$ \\
\hline Cardiovascular & & & \\
\hline Chest Pain & $34.2 \%(53 / 155)$ & $11.3 \%(6 / 53)$ & $0.7 \%(1 / 149)$ \\
\hline Palpitations & $0.6 \%(1 / 155)$ & $0(0)$ & $1.3 \%(2 / 155)$ \\
\hline Dermatologic & & & \\
\hline Rash & $1.3 \%(2 / 155)$ & $0(0)$ & $0.6 \%(1 / 155)$ \\
\hline Hair Loss & $0(0)$ & $0(0)$ & $0.6 \%(1 / 155)$ \\
\hline Gastrointestinal & & & \\
\hline Nausea/vomiting/diarrhea & $43.8 \%(68 / 155)$ & $7.3 \%(5 / 68)$ & $0.7 \%(1 / 150)$ \\
\hline Constitutional & & & \\
\hline Fever & $64.5 \%(100 / 155)$ & $1.0 \%(1 / 100)$ & $0(0)$ \\
\hline Chills & $32.9 \%(51 / 155)$ & $3.9 \%(2 / 51)$ & $0.6 \%(1 / 153)$ \\
\hline Myalgia & $41.2 \%(64 / 155)$ & $15.6 \%(10 / 64)$ & $4.1 \%(6 / 145)$ \\
\hline Fatigue & $36.7 \%(57 / 155)$ & $14.0 \%(8 / 57)$ & $8.2 \%(12 / 147)$ \\
\hline Neuropsychiatric & & & \\
\hline Loss of Taste & $41.2 \%(64 / 155)$ & $14.0 \%(9 / 64)$ & $0(0)$ \\
\hline Loss of Smell & $29.6 \%(46 / 155)$ & $19.5 \%(9 / 46)$ & $0(0)$ \\
\hline Confusion & $2.5 \%(4 / 155)$ & $0(0)$ & $2.6 \%(4 / 155)$ \\
\hline Headache & $22.5 \%(35 / 155)$ & $2.8 \%(1 / 35)$ & $5.2 \%(8 / 154)$ \\
\hline Dizziness & $5.8 \%(9 / 155)$ & $22.2 \%(2 / 9)$ & $2.6 \%(4 / 153)$ \\
\hline Insomnia & $0.6 \%(1 / 155)$ & $0(0)$ & $0.6 \%(1 / 155)$ \\
\hline Anxiety & $0(0)$ & $0(0)$ & $1.3 \%(2 / 155)$ \\
\hline Respiratory & & & \\
\hline Cough & $72.2 \%(112 / 155)$ & $25.8 \%(29 / 112)$ & $3.9 \%(5 / 126)$ \\
\hline Shortness of breath & $65.1 \%(101 / 155)$ & $18.8 \%(19 / 101)$ & $3.7 \%(5 / 136)$ \\
\hline & & & \\
\hline & & & \\
\hline
\end{tabular}




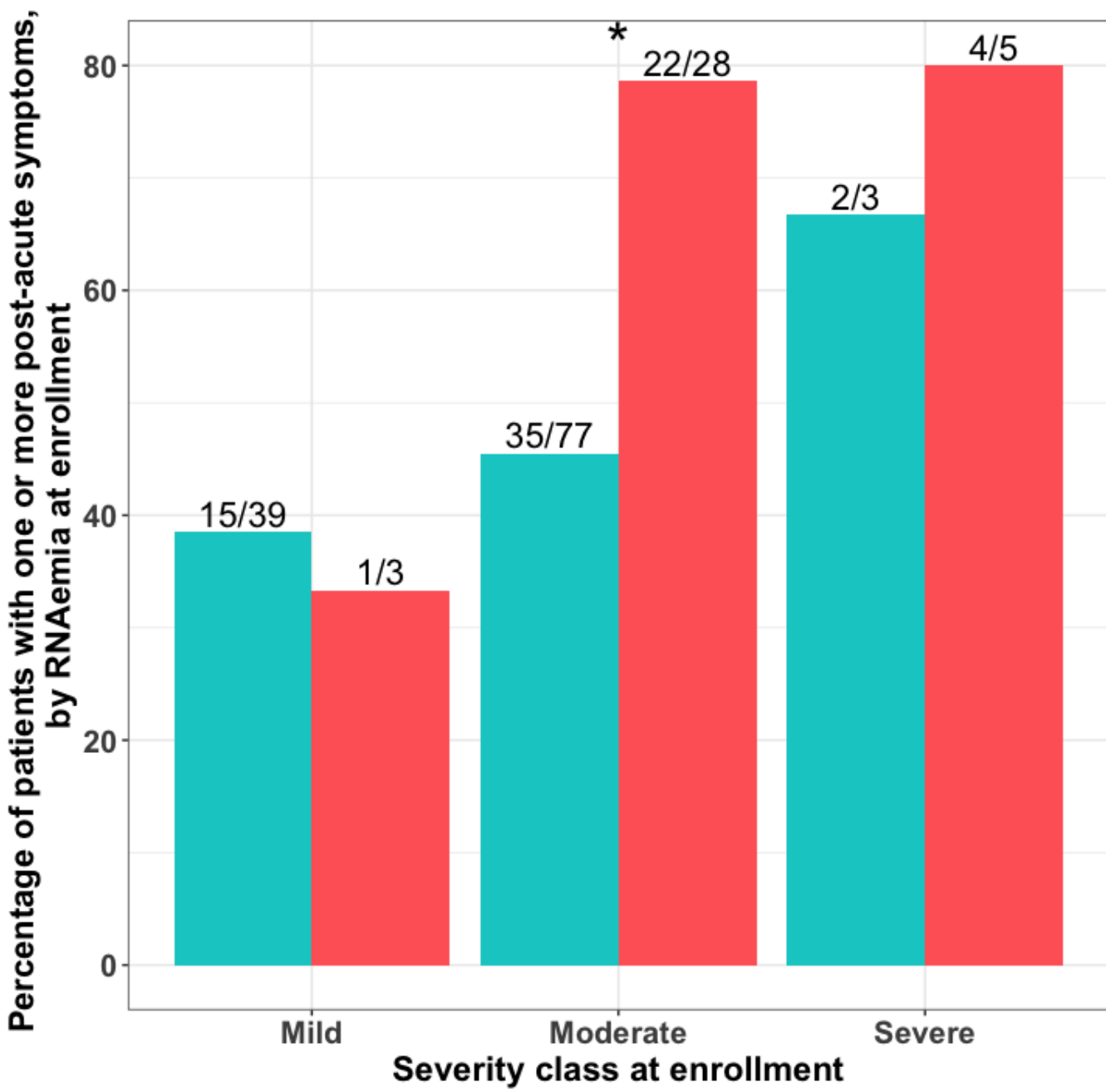

Non-RNAemic RNAemic

193 Figure. Rate of post-acute sequelae of SARS-CoV-2 infection, by RNAemia and clinical

194 severity on enrollment. Overall, 75.0\% (27/36) of initially RNAemic patients had one or more

195 post-acute symptoms at follow-up, compared to $43.7 \%$ (52/119) of non-RNAemic patients 196 (difference $=31.3 \%$ [95\% CI: $12.8 \%-49.8 \%], \mathrm{p}=0.002$ ). Conditional on severity at enrollment 197 (mild $=$ discharged from ED [n=42], moderate $=$ hospitalized, requiring no more than oxygen by 198 nasal cannula $[\mathrm{n}=105]$, severe $=$ hospitalized, requiring high-flow nasal cannula or mechanical 199 ventilation $[\mathrm{n}=8]$ ), RNAemia on presentation was associated with significantly higher rates of 
200 PASC for presentations of moderate severity (difference $=33.1 \%$ [95\% CI, $11.8 \%-54.4 \%$, $201 \mathrm{p}=0.005) . *$ indicates $\mathrm{p}$-value $<0.05$. 